\title{
Research on the Influence of Policies Guided Economy to Chinese Garment Industry and the Corresponding Innovation Education Pattern in Colleges and Universities
}

\author{
Jiarong $\operatorname{Han}^{1}$ \\ ${ }^{1}$ Northeast Dianli University ,Jilin , Jilin 132012 China
}

\begin{abstract}
In this paper, we research on the perspective of the influence of policies guided economy to Chinese garment industry and the corresponding innovation education pattern in colleges and universities. Currently, the world is undergoing profound changes, the economic globalization by leaps and bounds. Vocational school education shoulders the training a large number of skilled talents for the society and the mission of all kinds of specialized personnel. Train and bring up to adapt to the social needs of clothing professional skilled personnel and specialized talented person. In the future, we will conduct more related research to modify the current method and optimize it.
\end{abstract}

Keywords: Policies Guided Economy; Innovation Education; Garment Industry.

\section{Introduction}

At present domestic clothing enterprises are in a transition period, from passive to imitate processing enterprises to the brand management enterprise transformation, to the direction of diversification, urgent need a large number of design, understand technology, understand technology, beginning ability is strong, understand market trends to grasp the popular information and can accurately express the brand positioning style of senior specialized talents [1]. Higher vocational clothing related major construction should be guided by employment, active exploration, innovation, healthy development of the characteristic brand road. More specifically, clothing education is with the emergence of the clothing production, and gradually improved along with social progress and development. Although the clothing education in China starts late, but a long time in the groping stage, but also has for garment industry to provide a lot of high-level professionals and at the same time, of course, we should also be soberly aware that on the one hand, clothing enterprises lack of fresh blood has a pioneering spirit. On the other hand, many specially trained personnel of costume design in the enterprise also can't get reuse. As a engaged in the clothing education workers, especially the vocational high school clothing education workers, we should start from their own first, based on the actual can't think oneself once you choose this major after the well is a fashion design master.

Currently, the world is undergoing profound changes, the economic globalization by leaps and bounds. Rapid progress in science and technology, knowledge information increasingly makes the market competition [2]. With the rapid development of knowledge economy has every field has had a profound impact on the world. Social demand is motive power to promote the development of the economies. Social transition will lead to social demand structure of the profound change, lead to the change of the social production structure, industrial structure, the change of the pattern of economic development. Necessity demand satisfied after, will inevitably bring developmental needs of comprehensive and rapid growth. From necessity demand to the developmental demand, represents the transformation and upgrading of the structure of social demand, the objective will cause the change of economic structure. Policies to guide 
to the market and the market efficiency, promote competition. Important duty is to ensure that the market of government work, promote fair competition. Work and determination we will break industry monopolies and then break the regional monopoly, to break the administrative monopoly is an important part of the market play a role. Maintain the market order, maintaining the order of prices and prevent inflation and deflation, it is the requirement of market benign operation in the current time [3].

To combine the features of policies guided economy with garment industry and education, in this literature research, we point out the perspective of the influence of policies guided economy to Chinese garment industry and the corresponding innovation education pattern in colleges and universities. Due to the characteristics of apparel product itself is new, so the clothing education should also be based on now, look to the future, keep pace with The Times, when the training is given priority to with design of talents can't ignore the process operation, the market demand of knowledge learning. When training is given priority to with engineering talent also should strengthen the cultivation of aesthetics, design modelling ability training which should also master the certain knowledge of management. In the following sections, we will discuss in detail.

\section{Our Propose Novel Perspective}

The Basic Pattern of Garment Industry. After decades of rapid development in our country, the garment industry and other industries have made great progress and achievements and maintained for a long time the world first place on the garment producer and exporter, garment industry of the country's economic development has made important contributions [4]. China's clothing products structure is unreasonable, mainly cheap products, lack of high-end products, not only cause the profit levels of the industry, also affect the whole image of the Chinese clothing products, and this is mainly because China's garment industry development history is short, low level of technology accumulation. Form a complete set of scientific and technological innovation ability is poor, industry development lag behind. China's garment industry science and technology innovation, science and technology research and development ability is insufficient, enterprise very few high degree and the wide field of research and development personnel, enterprise research and development for new products is not value and related inadequate inputs. Industry production costs increase, sales of market competition. In recent years, domestic labor costs increased year by year, and raw materials rise in price, such as the superposition of two aspects effect lead to growing garment industry costs.

The traditional garment industry in China is from the previous quantity, price to win the extensive development to win by product quality, product ideas, product connotation to win business model innovation, to the transformation of management advantages to win, to ensure the vitality and competitiveness of garment industry. Higher apparel education to the development of garment industry provides a large number of professionals, in the face of garment industry in the development of new changes, to actively promote the clothing education reform, the training of specialists in the fields of more and better, to adapt to the clothing enterprise demand for talent.

The Influence of Policies Guided Economy. Policies to guide the first are the balance of the social total supply and total demand. Market economy can not only promote resource configuration to the social needs of most industries and priority link, and promote the resources use efficiency of different industries. Characterized by fair competition market economy, the competition must be - there are, the market main body in order to survive and win, must strive to improve their resource allocation efficiency, resource use efficiency, the allocation of resources to the industry of social need and the link you will get good economic benefit, they 
will continue to grow stronger. On the other hand, the market main body will shrink, or even be eliminated. Policies to guide to protect domestic market resources allocation efficiency, to protect domestic market and foreign market resources complementary benign, and safeguard domestic market overall efficiency is better than that of the international market. Market economy is the essential attribute of competition. Competition mechanism can be spontaneous promoting the market main body to expand production, the scale of production and promote technological innovation, to improve competitiveness, promote economic growth and become the driving force of economic growth. Market-oriented economic transition can promote technological progress. Market main body to seek its own survival and growth, so that as the change of the market and change their own production, management strategy in a timely manner to guide and constantly changing consumer preferences.

Policies to guide the economic transformation way could be separated into the following parts. (1) Planning guide. Macro economy as the main object mainly is to solve the national economic and social development of the long-term and significant problem. (2) Administrative interference. Administrative interference is the government using the administrative power to market, enterprises and the relevant economic activities conducted by the super economic administrative enforcement. (3) Legal norms. Market economy is legal economy, market economy rules need to be legalized. Law is the legal basis of macroeconomic regulation and control management. In the same industry, a market main body of resource utilization is more efficient and competitive power is strong, can obtain the industry average profit or excess profits, will grow, on the other hand, the resource utilization inefficiency, will atrophy and elimination.

The Relationship between Industry and Education. For people who cultivate people and cultivating what and how to cultivate people, is a good education work must resolve fundamental problems. Vocational school education shoulders the training a large number of skilled talents for the society and the mission of all kinds of specialized personnel. Train and bring up to adapt to the social needs of clothing professional skilled personnel and specialized talented person, is a good garment specialty construction important problem worth further discussing. Now some vocational school itself garment specialty not practical teaching phenomenon, equipment backward teaching ideas and methods of old, not adapt to the needs of society and other factors. In order to change clothing specialize teaching. In the traditional vocational school clothing teaching content set technology class, structure drawing class, intermediate class test setup, mainly for students focus on practice, traditional suit and Chinese tunic suit pants. But because of the development of The Times, Chinese tunic suit, clothing has gradually becoming the symbol for the particular historical period. The market demand in gradually reduce, so the curriculum to the teaching content should be improved.

According to the clothing enterprise the working process of the product development and production, set up professional courses. Product development and production of the enterprise including clothing market analysis, design, clothing structure design and garment production process. According to the requirement of the actual project design to carry out the teaching content of courses, class hours and course before and after the connection relationship. Course play have primary and secondary, overlapping each other, facilitate students will achieve mastery through a comprehensive professional skills, also facilitate implementation of engineering alternation in the process of teaching and productive practice and project teaching method.

The Novel Clothing Specialty Education Pattern. The global pattern of diversification, also calls for higher vocational education to set 
up corresponding time concept. Our education must be insisted on China's outstanding traditional culture at the same time, critically absorb the foreign culture. Foreign clothing colleges and universities teaching attaches great importance to the cultivation of the students skills and practice ability, some have begun to have practices and skills in the first semester class, such as saint Martin college of art and design the first year for students in a factory or studio practice and skill learning opportunities, students for the future of the professional direction and the design concept of development to lay a solid and competitive foundation. We should see the future of higher vocational clothing education must open road. Emphasis on classroom teaching and the education way of "industry-university-institute" cooperation work in enterprise, the company field including internship alternates, truly realize the interaction between school education and enterprise production, optimizes the allocation of education resources, implement intensive inter-school cooperation, cooperation between colleges and share resources, share the results. In addition, to give students more confidence and practice guidance, to cultivate their long-term perspective, to cultivate students' ability to solve practical problems of production, to improve the quality and efficiency of education. We should have the corresponding basic skill training fine condition of experimental teaching base and a large number of garment enterprises as a stable students training and practice base to make students get more system, perfecting the practice of education.

Clothing education teaching reform to improve, the students' professional quality is also improved obviously. We point out that from the following perspective, we could solve the important issues well. (1) Improving the teaching of basic drawing mode. Costume design drawing does not need to pass by the geometric form which still life to plaster model, head to the body, bust and deep felt such a shallow person, so careful rigorous basic training process. Because clothing painting is just a small part of the clothing system engineering, most of the time should be used for the shape and structure change, production process of clothing, clothing materials, etc. (2) Develop the students' ability of creative thinking. Clothing design is the core of thinking ability, thinking ability is the highest level of creative thinking. Can say now, especially after elements contain in costume design if there is no innovation, it is difficult to have a foothold in the market, so we must pay attention to in teaching to develop students' imagination and creative thinking ability in this respect which uses the many kinds of teaching means to cultivate students' creative thinking, in order to achieve good teaching effect. (3) To strengthen the guidance of the learning method of students. Today's design combined with industry and the marketing plan has been in the scope of product development and design value creativity, not only is more of an emphasis on understanding the social and consumer lifestyle, more practical in the expression and implementation. (4) Clothing style and structure of the integrated teaching. Clothing modelling and the changing structure of the unified style, is the most key link in the clothing design, also the backbone in teaching content. Will only draw renderings and cannot be produced accordingly reasonable structure, design also can only be an armchair strategist; Instead just learn that have shaped the conventional clothing structure, not flexible, also can't be learned to design. We believe that through the proposed reform, the education will be more effective.

\section{CONCLUSIONS}

In this paper, we research on the perspective of the influence of policies guided economy to Chinese garment industry and the corresponding innovation education pattern in colleges and universities. Higher apparel education of our country together with the garment industry development, cultivate a large number of talents 
for the development of garment enterprises, but as a result of higher apparel education of our country are developed in certain stage of social and economic reform, the development history is shorter, level is not high, there are many shortcomings. Garment industry in the development of the new situation puts forward new requirements for clothing industry, higher apparel education how to combine the development of the apparel industry new need to reform the existing education teaching is very important. Our research in the paper solves the issues well.

\section{Acknowledgement}

This research is financially supported by the project of Jilin province department of education (2012). The project number for our research is GH14110.

\section{References}

[1] Yang G Z. Evolution and international comparison of export competitiveness of textile and garment industry of China[J]. Wool Textile Journal, 2014.

[2] Fang-Lan X U. Analysis and Inquiry of China's Luxury Consumption Market:a Case Study of Men's Garment Industry[J]. Prices Monthly, 2014.

[3] Xian-An H E. Automatic System in the Analysis of Application of the Modern Garment Industry[J]. Equipment Manufacturing Technology, 2014.

[4] Jajri V N I. The garment industry in Laos: technological capabilities, global production chains and competitiveness[J]. Asia Pacific Business Review, 2014, 20(2):318-320. 